\title{
Pioneering Objectives and Activities on the Surface of Mars
}

\author{
Larry Toups ${ }^{1}$ \\ NASA Johnson Space Center, Houston, Texas, 77058 \\ and \\ Stephen J. Hoffman, Ph.D. ${ }^{2}$ \\ Science Applications International Corporation, Houston, Texas, 77058
}

Human Mars missions have been a topic of sustained interest within NASA, which continues to use its resources to examine many different mission objectives, trajectories, vehicles, and technologies, the combinations of which are often referred to as reference missions or architectures. The current investigative effort, known as the Evolvable Mars Campaign (EMC), is examining alternatives that can pioneer an extended human presence on Mars that is Earth independent. These alternatives involve combinations of all the factors just mentioned. This paper is focused on the subset of these factors involved with objectives and activities that take place on the surface of Mars. "Pioneering" is a useful phrase to encapsulate the current approach being used to address this situation - one of its primary definitions is "a person or group that originates or helps open up a new line of thought or activity or a new method or technical development". Thus, in this scenario, NASA would be embarking on a path to "pioneer" a suite of technologies and operations that will result in an Earth independent, extended stay capability for humans on Mars. This paper will describe (a) the concept of operation determined to be best suited for the initial emplacement, (b) the functional capabilities determined to be necessary for this emplacement, with representative examples of systems that could carry out these functional capabilities and one implementation example (i.e., delivery sequence) at a representative landing site, and will (c) discuss possible capabilities and operations during subsequent surface missions.

\footnotetext{
${ }^{1}$ Systems Engineer, Exploration Mission Planning Office, 2101 NASA Parkway/Mail Code XM, Houston, TX, 77058.

${ }^{2}$ Systems Engineer, Exploration Mission Planning Office, 2450 NASA Parkway, Houston, TX, 77058.
} 


\section{Introduction}

How do we pioneer an extended human presence on Mars that is Earth independent?

THIS question has been a topic of discussion in technical studies and fictional accounts over the years, but it is a new facet that has been added to NASA's studies of future human missions to Mars. As a first step in addressing this question, a common understanding of several key terms and phrases in the context of NASA's Evolvable Mars Campaign (EMC) was needed, specifically: (a) What is meant by "pioneering?" (b) How long is "an extended human presence?" and (c) What is meant by "Earth independence?" A common understanding of each of these items is important to help guide subsequent assessments and trades between otherwise equivalent options.

After considering the various definitions of "pioneer" or "pioneering," attention was focused on a meaning that emphasized "a person or group that originates or helps open a new line of thought or activity or a new method or technical development" (Ref. [1]). This meaning emphasized the development of new technologies and operations that will be needed for human crews to live and work on the surface of Mars for some yet-to-be-determined period of time. It also de-emphasized another common meaning for this term: that of settling or colonizing a new territory, which seemed to run counter to the general intent of the EMC.

A specific duration to characterize "extended human presence" was open to a wide range of possibilities. For example, the amount of time spent by a single individual on the surface could be used to gauge an "extended ... presence," or the collective time spent by entire crews over some interval of calendar time could be used. While each of these options has its utility in various situations, a decision was made to use a two-level definition: a threshold goal of remaining on the surface for a minimum of 12-18 months and an ultimate goal of remaining on the surface indefinitely. The threshold goal indicates a level of confidence in systems and operations that allows crews to remain on the surface for the entire duration in the Mars vicinity as determined by "long stay" trajectories assumed for these missions (as opposed to short stays on the surface with long stays spent in orbit around Mars between the trajectory-defined arrival window and departure window). The ultimate goal is an indication that systems, operations, and use of local resources have reached a level of maturity such that an individual, or an entire crew, would leave the surface as a matter of choice rather than necessity.

For the final phrase, "Earth independence," attention was focused on a meaning that emphasized "not requiring or relying on others (as for care or livelihood)" along with several useful synonyms, including self-sufficient, selfreliant, self-supporting, and self-sustaining (Ref. [2]). 
Using these terms to clarify the meaning of the question as originally posed results in the following:

"How do we develop new ideas, methods, technologies, systems, and operations that enable humans to initially remain on the surface of Mars for a minimum of 12 - 18 continuous months (as determined by the arrival and departure dates of "long stay" trajectories and in-space propulsion) and ultimately remain on the surface indefinitely (leaving only as a matter of choice, not necessity), without requiring or relying on support from Earth for routine operations; a selfsufficient, self-reliant, self-supporting, self-sustaining infrastructure?"

As the meaning of these phrases was being discussed, it was apparent that before an Earth independent, indefinite stay time can be achieved, there are "known unknowns," and very likely "unknown unknowns," that can only be addressed and understood by human crews living and working on Mars. This led to the concept of a "Mars Surface Proving Ground" - a period of time along the path of achieving Earth independence during which solutions for these unknowns would be tested and a set of "best practices" results would be identified and characterized. Several of these "known unknowns" that would be investigated during this "Mars Surface Proving Ground" phase include:

- Human physiological reaction to the Mars environment (e.g., gravity, radiation, dust, etc.)

- Plant physiological reaction to the Mars environment (e.g., gravity, radiation, lighting, etc.)

- Sources and extraction/processing technology for water

- Martian civil engineering "best practices" (e.g., surface preparation/stabilization)

- Martian chemical engineering "best practices."

The "unknown unknowns" are, by definition, unknown but not unanticipated. So, as a general guiding principle, surface infrastructure would be implemented in such a way that it is adaptable and has built-in margin to accommodate different (than originally planned) activities without requiring a complete redesign and redeployment. One well-established concept that is used to handle "unknowns" is the field station or experiment station. Field stations create a bridge between natural environments and (Earth-based) research laboratories. Research laboratories offer considerable power to conduct analyses in a predictable environment and to infer cause and effect from manipulative experiments, but they may miss factors that turn out to be critical in a natural environment. Field studies can encompass the full range of relevant interactions and scales, but they are not as tightly controlled. By 
offering access to both laboratories and field environments, Field Stations combine the best of both worlds (Ref. [3]).

A Mars Surface Field Station thus provides a useful construct to help visualize the range of scientific investigations and applied technological research that would be conducted by human crews along with the range of infrastructure needed to support these activities. The combination of utilizing a Mars Surface Field Station within a "Mars Surface Proving Ground" approach with the goal of achieving an "extended presence" led to a three-phase architecture for the evolution of capabilities and activities conducted by human crews on the surface of Mars (Fig. 1).

\section{Emplacement}

(Threshold Goal) 12-18 month stay enabled

1

Earth independence for that time period

\section{Mars Surface Proving \\ Ground}

Mars Surface Field Station

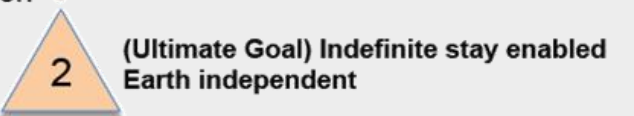

Phase 1

Phase 2

Phase 3

Fig. 1 A three-phase architecture for the evolution of capabilities and activities conducted by human crews on the surface of Mars.

\section{Phase Descriptions}

The primary objective during the Emplacement phase would be to establish an initial human presence on the surface of Mars. This objective is characterized by several key factors:

- Development of an interplanetary transportation system, entry/descent/landing system (EDL), and basic habitation needs for human crews, 
- $\quad$ Establishment of surface equipment and science instruments, and

- $\quad$ Laying the foundation for future, more complex surface operations.

Activities during this phase would be focused on certifying both human crews (i.e., physiological and psychological suitability) and basic infrastructure (i.e., habitation and power systems) to operate on the surface for 12 - 18 continuous months without resupply. Human crews would explore at ranges of tens of kilometers away from the surface facilities; robotic systems would explore tens to hundreds of kilometers away.

The primary objective of the Mars Surface Proving Ground phase would be to develop a deeper understanding of the Mars environment and how to live/work within the constraints it imposes. This objective is characterized by several key factors:

- Developing and testing alternative combinations of systems and operations that will break reliance on Earth in those areas not already achieved during the Emplacement phase, including expanded reliance on local resources,

- Improving confidence in overall operational strategies; day-to-day activities are conducted without continual supervision and guidance from support staff on Earth.

Activities would be focused on breaking the reliance on Earth in those areas not already achieved during the Emplacement phase, including expanded utilization of local resources. Human and robotic operations would also be routinely conducted at ranges of hundreds of kilometers from the outpost. This is the phase during which a Mars Surface Field Station would be established.

Activities on Mars would transition to the Utilization phase when basic Earth independence has been demonstrated. This objective is characterized by several key factors:

- Crews of up to four people are certified to remain indefinitely at the surface outpost with minimal (ideally zero) resupply,

- A continuous crew presence is maintained on the surface (attained via crew rotation),

- $\quad$ Routine use of, and reliance on, in situ resources (i.e., more than just propellants or breathing gases) to support and sustain the crew and infrastructure operations.

The area for exploration opportunities would be expanded to include routine human access to more distant points on the planet (many hundreds to thousands of kilometers). 
Through all of these phases there would be an ongoing series of experiments and demonstrations, as well as an expansion of surface infrastructure, to make progress towards Earth independence. Figure 2 summarizes how this progression might be implemented through In Situ Resource Utilization (ISRU).

\section{Emplacement \\ - Baseline \\ - $\mathrm{O}_{2}$ production for Mars Ascent Vehicle (MAV) and life support \\ - Should be baselined for $1^{\text {st }}$ mission: \\ - Resource exploration \& prospecting (surveying, mapping, subsurface sampling \& characterization) \\ - Trash processing (once crew arrives) for propellant}

\section{- Options for $1^{\text {st }}$ mission}

- Terrain shaping (leveling, consolidation, berm building, site surveying, surface assets protection, etc.)

- Water extraction from soil for life support, MAV propulsion, and fuel cell reactants

- Nitrogen for habitats

- Landing zone construction

- Repurposing

\section{Mars Surface Proving Ground Utilization}

- ISRU support of Mars Field Station capabilities

- Resource exploration \& prospecting

$-\mathrm{O}_{2}, \mathrm{H}_{2} \mathrm{O}$, and $\mathrm{CH}_{4}$ production for life support, propulsion, \& fuel cells

- Trash processing (once crew arrives) for propellant and planetary protection

- Scientific exploration support (trenching to expose subsurface features, subsurface instruments emplacement)

- Landing zone construction

- Establish consumable fluid depot; transfer capabilities for $\mathrm{O}_{2}, \mathrm{CH}_{4}$, and water

- Demonstrate capabilities for Utilization

- Cleaning products for science and planetary protection

- Gases for purging systems, esp. dormant

- Metals production for parts manufacturing

- Additive 3D regolith constructions

- Plastic production with ISRU products

- Nutrient/food production with ISRU products

Fig. 2 One possible progression of increasing capabilities and use of in situ resources through a threephased Mars surface exploration architecture to achieve Earth independence (ISRU)

\section{Emplacement Phase Options}

When looking at an Emplacement/Mars Surface Proving Ground/Utilization phased architecture, the approach was not to develop one case study, but to first identify and compare possible options, and then to perform a top-level assessment of those options. However, there was a particular focus on the basic infrastructure and concept of operation for the Emplacement phase.

To enable the Emplacement phase, five top-level decision criteria were identified that informed an options tree: Emplacement phase duration (minimized or stretched), surface mission duration (500 or 300 sols), habitat architecture (modular or monolithic), logistics carrier (10t or $5 \mathrm{t}$ capability), and the surface lander payload capability (27t or 18t). 
Figure 3 illustrates the relationship among these options and, as can be seen, results in 32 cases to consider when looking at the overall campaign for the EMC.

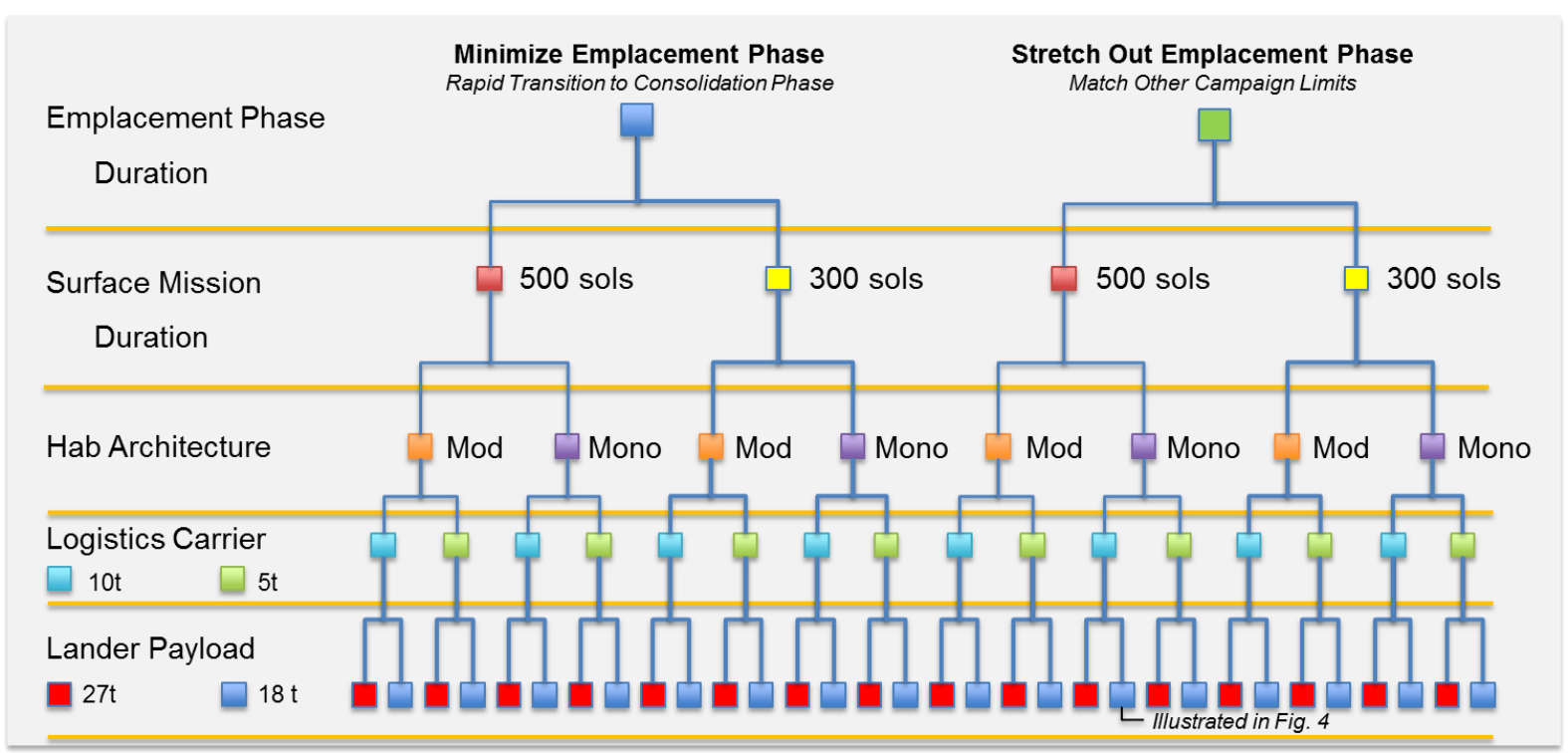

Fig. 3 Options under consideration for surface infrastructure deployment and initial crew operations during the Emplacement phase.

On the first tier of this option tree are two cases related to the point in the overall campaign at which the Emplacement phase is complete. One option, labeled "Minimize Emplacement Phase" in Fig. 3, is to deliver all of the infrastructure prior to the arrival of the first crew. This allows the first crew to immediately begin the full range of surface activities envisioned for the start of the Mars Surface Proving Ground phase; i.e., exploration of distant regions of interest (ROIs) as well as initiation of applied technological research at or near the Mars Surface Field Station. The other option, labeled "Stretch Out Emplacement Phase," defers the delivery of some of the surface infrastructure elements and/or decreases the logistics delivered, thus shortening the surface stay time for early crews. This could reduce the number of cargo landers needed before the first crew can land or could match other pacing items within the EMC (e.g., Space Launch System launch rate).

On the second tier are two options that bound the surface stay time as determined by the in-space transportation system and the trajectory opportunity. It is always possible to stay for a shorter period of time than the two values indicated here, but these values, 300 and 500 sols, provide an indication of the amount of consumables and logistics that would be required for two "representative" surface stay durations and thus set the size or volume needed in certain key surface infrastructure elements, such as the crew habitat. For some low thrust transportation systems and their associated trajectories, the arrival and departure times set by orbital mechanics is relatively constant at about 
300 sols. For other transportation options that combine chemical and low thrust systems, the arrival and departure times vary from one trajectory opportunity to the next within the range of approximately 300 to 500 sols (Ref. [4]).

The third tier represents options for the surface habitation architecture, still being evaluated within other EMC studies. These two habitat architectures are a monolithic habitat (abbreviated "mono" in Fig. 3) and a modular habitat (shown in Fig. 3 as "mod"). The monolithic option indicates that a single habitat structure is delivered to the surface with all subsystems and capabilities necessary to support the crew. A modular habitat divides subsystems among two or more structures that must be integrated on the surface before the crew can use this system. Because analysis of the modular concept is still in work, it was not included in this study.

The fourth tier represents options for a new element that has been added during the most recent assessments: a logistics carrier. Each arriving crew will require a certain amount of consumables, logistical supplies, spare parts, etc. to support them during their surface mission. These supplies will need to be transported in something that protects the contents during launch, transit, and entry at Mars, and will maintain a reasonable internal environment prior to the arrival of the crew, which could be many months, or even years. Concepts for two different logistics carriers have been developed, defined by the overall mass of the carrier and its content. Both were selected to be compatible with those systems used to offload payloads from the cargo lander and transport cargo across the surface. The so called " 5 ton" carrier (the name originating from a target size for this carrier) resulted in a concept with an empty mass of $2560 \mathrm{~kg}$, able to hold up to $3100 \mathrm{~kg}$ of cargo. The " 10 ton" carrier concept has an empty mass of $3130 \mathrm{~kg}$ and is able to hold up to $5770 \mathrm{~kg}$ of cargo.

The fifth and final tier is for the two Mars surface lander options still being evaluated within the EMC. The designation for each of these options - 18 ton and 27 ton - is an indication of the cargo mass that each lander can deliver to the surface.

An observation that is common across all of these assessments is that the fixed size of each of the payload elements, including the logistics carriers, and the fixed cargo mass capacity of the landers means that each lander is never filled to its maximum capacity. Similarly, the fixed capacity of the logistics carrier, which must in turn be carried on a fixed capacity lander, means that the logistics carriers are typically never filled to capacity. This means that the landers and logistics carriers used to deliver each crew to Mars will have some unallocated payload capacity in the manifests developed by these assessments. Given the current level of maturity for individual payload elements and the logistics needed to support people on Mars, the magnitude of this unallocated payload capacity is likely to 
change over time. But even as knowledge of these payload items matures, there will always remain some amount of unallocated payload capacity. This could be filled with useful items that can be easily scaled to match the capacity available - items such as water, or the raw material used by additive printing systems.

Results from the assessments to date are summarized in Tables 1 and 2. These assessments looked at the first three crew increments sent to Mars. Three crew increments were chosen to see the effects they had in the first tier of the option space, while also being sufficient to reach the end of the Emplacement phase. An illustrative example manifest showing the sequence in which these payload items are delivered for one of these assessments is shown in Fig. 4 and noted in Fig. 3.

A note of caution: all of these assessments are based on the payload mass being carried on each lander. The volume of the payload items, however, has not been examined at an equivalent level of detail. A volumetric assessment is also needed to determine if the number of landers and the payload complement on each lander can be accommodated within both the mass limits and volume limits of lander concepts.

Table 1. Results from evaluation of monolithic habitats and minimizing the Emplacement phase for Mars surface infrastructure deployment and initial crew operations.

\begin{tabular}{|c|c|c|c|c|c|c|c|c|}
\hline $\begin{array}{r}\text { Emplacement Phase } \\
\text { Duration }\end{array}$ & \multicolumn{8}{|c|}{ Minimize Emplacement Phase Duration for Rapid Transition to Consolidation Phase } \\
\hline Surface Mission Duration & \multicolumn{4}{|c|}{500 sols } & \multicolumn{4}{|c|}{300 sols } \\
\hline Hab Architecture & \multicolumn{4}{|c|}{ Monolithic } & \multicolumn{4}{|c|}{ Monolithic } \\
\hline Logistics Carrier & \multicolumn{2}{|c|}{ 10-ton } & \multicolumn{2}{|c|}{ 5-ton } & \multicolumn{2}{|c|}{ 10-ton } & \multicolumn{2}{|c|}{ 5-ton } \\
\hline Lander Payload & 18-ton & 27-ton & 18-ton & 27-ton & 18-ton & 27-ton & 18-ton & 27-ton \\
\hline Lander \# of $1^{\text {st }}$ Crew & 6 & 4 & 6 & 4 & 5 & 3 & 5 & 4 \\
\hline $\begin{array}{r}\text { Unallocated Mass Through } \\
\text { 1st Crew Launch }(\mathrm{kg})\end{array}$ & 15,218 & 21,618 & 9,818 & 17,638 & 4,949 & 2,349 & 1,512 & 27,289 \\
\hline Lander \# of $2^{\text {nd }}$ Crew & 9 & 6 & 9 & 6 & 7 & 5 & 8 & 6 \\
\hline $\begin{array}{r}\text { Unallocated Mass Through } \\
2^{\text {nd }} \text { Crew Launch }(\mathrm{kg})\end{array}$ & 30,406 & 36,876 & 21,026 & 28,916 & 6,005 & 21,405 & 19,078 & 44,925 \\
\hline Lander \# of $3^{\text {rd }}$ Crew & 12 & 8 & 12 & 8 & 9 & 7 & 11 & 8 \\
\hline $\begin{array}{r}\text { Unallocated Mass Through } \\
3^{\text {rd }} \text { Crew Launch }(\mathrm{kg})\end{array}$ & 45,594 & 52,134 & 32,234 & 40,194 & 7,061 & 40,461 & 36,644 & 62,561 \\
\hline
\end{tabular}


Table 2. Results from evaluation of monolithic habitats and stretching out the Emplacement phase for Mars surface infrastructure deployment and initial crew operations.

\begin{tabular}{|c|c|c|c|c|c|c|c|c|}
\hline $\begin{array}{r}\text { Emplacement Phase } \\
\text { Duration }\end{array}$ & \multicolumn{8}{|c|}{ Stretch Out Emplacement Phase Duration to Match Other Campaign Limits } \\
\hline Surface Mission Duration & \multicolumn{4}{|c|}{500 sols } & \multicolumn{4}{|c|}{300 sols } \\
\hline Hab Architecture & \multicolumn{4}{|c|}{ Monolithic } & \multicolumn{4}{|c|}{ Monolithic } \\
\hline Logistics Carrier & \multicolumn{2}{|c|}{ 10-ton } & \multicolumn{2}{|c|}{ 5-ton } & \multicolumn{2}{|c|}{ 10-ton } & \multicolumn{2}{|c|}{ 5-ton } \\
\hline Lander Payload & 18-ton & 27-ton & 18-ton & 27-ton & 18-ton & 27-ton & 18-ton & 27-ton \\
\hline Lander \# of $1^{\text {st }}$ Crew & 5 & 3 & 5 & 3 & 5 & 3 & 5 & 3 \\
\hline $\begin{array}{r}\text { Unallocated Mass Through } \\
\text { 1st Crew Launch }(\mathrm{kg})\end{array}$ & 5,850 & 3,850 & 3,010 & 920 & 13,511 & 10,981 & 7,101 & 3,801 \\
\hline Lander \# of $2^{\text {nd }}$ Crew & 8 & 5 & 8 & 5 & 8 & 5 & 8 & 5 \\
\hline $\begin{array}{r}\text { Unallocated Mass Through } \\
2^{\text {nd }} \text { Crew Launch }(\mathrm{kg})\end{array}$ & 12,476 & 6,816 & 5,656 & 2,036 & 23,935 & 21,475 & 19,105 & 12,875 \\
\hline Lander \# of $3^{\text {rd }}$ Crew & 11 & 7 & 11 & 7 & 10 & 7 & 11 & 7 \\
\hline $\begin{array}{r}\text { Unallocated Mass Through } \\
3^{\text {rd }} \text { Crew Launch }(\mathrm{kg})\end{array}$ & 27,664 & 18,944 & 15,864 & 13,314 & 24,991 & 40,531 & 36,671 & 30,511 \\
\hline
\end{tabular}

Comparing results for the first tier option, minimizing the Emplacement phase requires either five to six 18 -ton landers or three to four 27-ton landers. A stretched out Emplacement phase requires the arrival of one or more of the small pressurized rovers and some of the science infrastructure to be deferred until after the first crew's landing. Habitation and power were always required, and logistics mass (plus the mass of the logistics carriers) was set by the duration of the surface mission. So, delaying Emplacement phase completion until sometime after the first crew's mission typically saves only one lander for each of these cases (i.e., five 18-ton landers instead of six, or three 27-ton landers instead of four).

Second tier option results show that a 300 sol surface stay did result in a lower amount of mass delivered to the surface, but this typically did not result in a lower number of landers. The difference in mass for consumables, logistics, spares, etc. was not large enough to allow the other payloads to be redistributed among a smaller number of landers. It appears that a surface stay of less than 300 sols will result in a mass savings sufficient to reduce the number of landers needed, but there was insufficient data to find the break point.

Third tier options (monolithic versus modular habitats) could not be compared because data for the modular habitat option is not yet available. However, it should be noted that the monolithic habitat mass, currently estimated to be over 23 tons, exceeds the 18-ton lander cargo mass capacity. For purposes of this assessment, it was assumed 
that a sufficient amount of habitat internal systems could be delivered separately, so that the remainder of the habitat was compatible with the 18-ton lander, and the off-loaded systems could then be integrated by the crew after their arrival.

Comparing results for the fourth tier, logistics carrier options made a significant impact on the overall surface mission concept of operations, both positive and negative. The mass of these logistics carriers is substantial. In some cases, this additional mass resulted in the need for an additional lander when compared with previous analyses in which no logistics carrier mass was included in the manifest. However, these logistics carriers also represent additional useful infrastructure. Because they are pressurized and have basic subsystems to maintain the internal environment for the cargo they carry, there is an opportunity for reconfiguration and alternative use once their cargo delivery function is completed (i.e., during the Mars Surface Proving Ground Phase).

Comparing results from the fifth and final tier, it can be seen that the 18-ton lander typically requires five or six landers to deliver the first crew increment and then three or four landers for each subsequent crew increment. The 27-ton lander typically requires three or four landers to deliver the first crew increment and then two landers for each subsequent crew increment. Two landers represents the minimum number of landers that are required regardless of the payload capacity - one lander to deliver the Mars Ascent Vehicle (MAV) for that crew and the second lander to deliver the crewmembers. Cargo for this crew could be delivered on either of these lander options, but the number of landers cannot be reduced. This results in a large amount of unallocated payload mass on each lander. For missions after the Emplacement phase, this unallocated payload mass will be used, in part, for additional systems and infrastructure for the Mars Surface Proving Ground phase. However, specific systems and the associated mass for these systems has yet to be assessed. 
Long Emplacement - Full Infrastructure Not in Place Until $2^{\text {nd }}$ Crew

Lander: 18-ton Habitat: Monolithic Stay Time: 500 sols Cargo: 10-ton Logistics Carriers

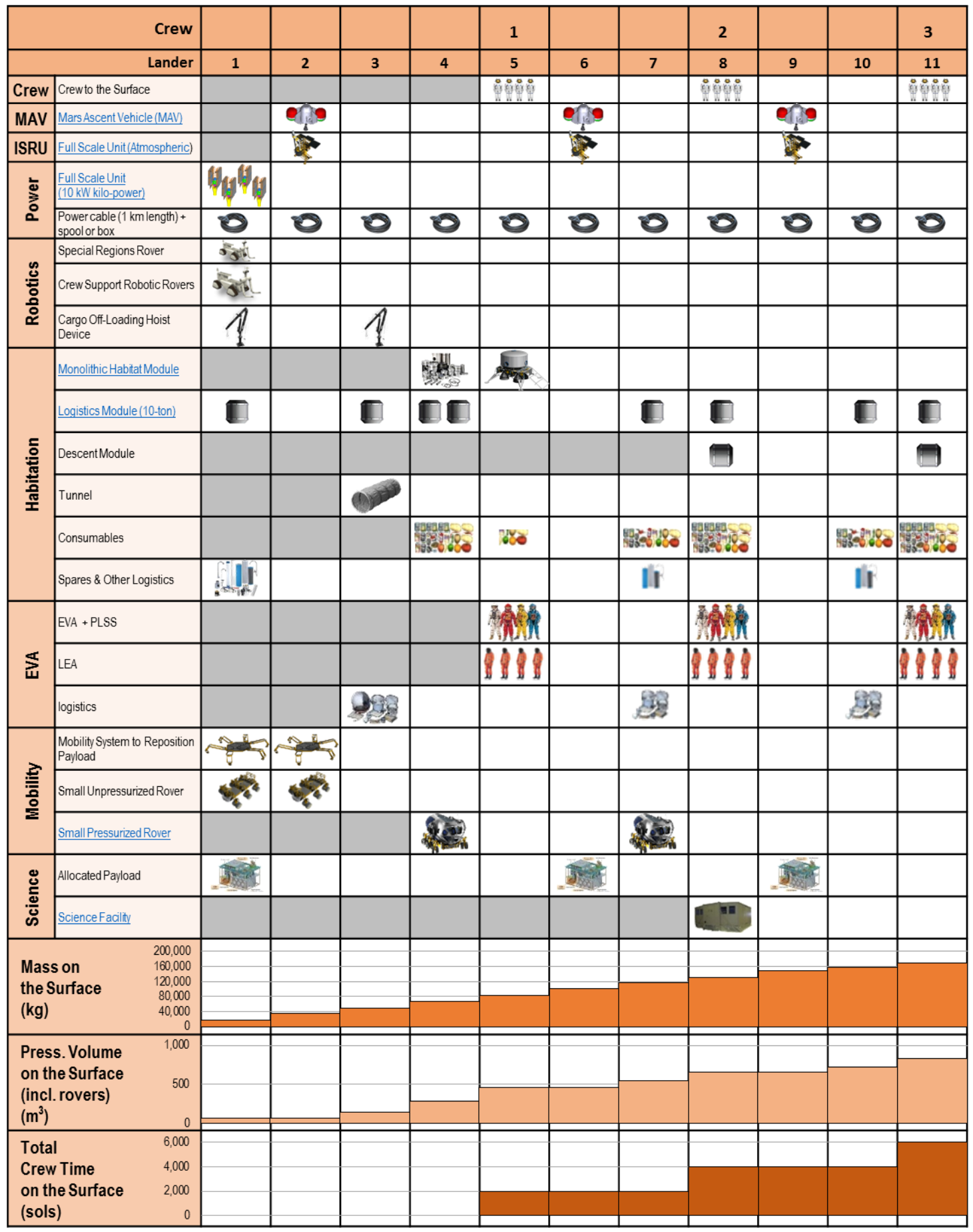

Fig. 4 A summary of one case from among the options being evaluated for the Emplacement phase of Mars surface operations. This case uses 18-ton landers and 10-ton logistics carriers and completes the Emplacement phase during the mission of the second crew. 


\section{Mars Surface Proving Ground and Utilization Phases}

Once the primary Emplacement phase objective is met, enabling crews to remain on the surface of Mars for 12 18 months, this infrastructure and experience base will be used as the foundation for building the capabilities needed for the Mars Surface Proving Ground phase and the establishment of a Mars Surface Field Station. Priority should be given to investigating the "known unknowns," with flexibility to investigate "unknown unknowns" as they emerge. One well-established concept that is used to handle "unknowns" is the field station. Field Stations bring the basic tools of research - from electricity to communication to community — to the places where research needs to be done, and cultivate a base of knowledge that fosters discovery. They provide access to the environment and provide logistical support for a wide range of activities, including individual research projects and networking of research on larger scales in science, technology, engineering, and public outreach. Field Stations create a bridge between natural environments and research laboratories. Research laboratories offer considerable power to conduct analyses in a predictable environment and to infer cause and effect from manipulative experiments, but they may miss factors that turn out to be critical in a natural environment, such as that found on the surface of Mars (Ref. [3]). By offering access to both laboratories on Earth and field environments on Mars, a Mars Surface Field Station combines the best of both worlds.

The top level capabilities needed in a Mars Surface Field Station include:

- Habitation for at least four crew with surge capacity

- Continuous occupancy with surge capability to eight crew for extended periods of time (many months)

- ISRU

- Retain capability to use atmosphere to generate oxygen for ascent propellant and other applications on the surface

- Generate sufficient water for use by crew and to support crop growth

- Power

○ Full-scale power system $(40 \mathrm{~kW})$ for ISRU

○ Power generating capacity augmentation for continuous occupancy and additional capabilities (e.g., crop growth)

- EVA

- EVA for crew sorties out of habitat and out of small pressurized rovers 
○ On-site repair in addition to simple maintenance

- Mobility

- Small pressurized rovers (SPRs), primarily for long-range traverses, with unpressurized rovers (primarily for local traverses and to assist in contingency situations with the SPRs when long-range traverses are underway)

○ Robotic rovers to support science investigations and ISRU activities

○ Mobility devices to move cargo and systems from landers to usage locations

○ On-site repair in addition to simple maintenance

- Science

- Expanded equipment to address discoveries and refinement of previous experiments

- Food production

- Provide $50 \%$ of consumables for four crew as an initial goal

- On-site construction and manufacturing

- Equipment for significant reshaping of local terrain (e.g., leveling, excavating, berm construction, etc.)

- Equipment to manufacture small parts typically used in repair of surface infrastructure systems

A key objective of the Mars Surface Field Station would be to validate system and subsystem reliability, maintainability and sustainability. The systems and subsystems demonstration and validation could include the following: Habitat Design and Development, Closure of Life Support Systems, Plant Adaptation leading to Food Production, Medical Sciences (Human Adaptation) Research, EVA Testbed, Navigational Systems, Radiation Shielding Using Natural Materials, Regolith Excavation and Movement Technology, Surface Mobility Systems (Robotic and Piloted), Dust Mitigation Techniques, Parts Fabrication Demonstration, Ergonomics Research, Research Utilization Studies, Environmental Degradation Abatement Tests, Launch and Landing Activities, and Inspection/Maintenance/Repair Operations. For example, a new inflatable habitat design could be demonstrated at a system level, while techniques for inflating and rigidizing inflatable habitats could be demonstrated at a subsystem level.

So, the next question posed is:

What capabilities or experience level should mark the readiness to transition from the Mars Surface Proving Ground to the Utilization (Earth Independence) phase? 
1. A continuous crew presence is established - For this objective, "Continuous Crew Presence" means sufficient infrastructure has been established on the Martian surface and sufficient confidence has been built up in the reliability and operation of this infrastructure such that Crew Increment A does not leave the surface until Crew Increment B arrives and a hand-off has taken place. Some of the key infrastructure items that fall into this category include habitation (including life support), radiation protection, food production for a substantial fraction of the crew's needs, and either sufficient stocks of replacement parts or the existence of a local ISRU-supported manufacturing capability that is able to make the parts necessary to maintain this key infrastructure, even if one or two logistical resupply opportunities are missed. The selected in-space transportation system will have much to do with defining an individual's "tour of duty" at Mars, but this is likely to be measured in (Earth) years rather than months.

2. Radiation protection is provided from SPEs and GCR in the primary habitat - For this objective, "radiation protection" means primary habitation elements are protected from SPEs and GCR to some yet-to-bespecified level (ideally to Earth surface ambient) using locally derived materials. While the crew exposure limit will need to be determined, the combined effect of shielding and medical countermeasures must be taken into account in that determination. Several approaches have been proposed that could achieve this level of protection, including the use of locally-obtained water in habitat walls/ceilings, using Martian regolith on the exterior of habitats, burying habitation structures, or forming walls and roofs using various construction techniques.

3. The ability to produce a yet-to-be-specified percentage of the crew consumables is provided - For this objective, the capability would be in place to reliably produce the majority of the food needed for a balanced diet in the Mars surface environment. Previous experiments (e.g., the JSC Regenerative Life Support System Laboratory) led to the following estimates: 10 sq. meters/person for air and water revitalization, $35-40$ sq. meters/person for air and water revitalization plus $\approx 80 \%$ food needs. Note: these values are for the "canopy area" allocated to the crops, not the "floor space" used. A larger canopy area can be accommodated in a smaller floor space by stacking or 'bunking' tiered plant growth trays vertically. To provide $\approx 80 \%$ of food production needs for a crew of 4 requires about 160 sq. meters of crop growth area. To provide $\approx 80 \%$ of food production needs for a crew of 8 requires about 320 sq. meters of crop growth area (Ref. [5]). 
4. The need for infrastructure support (e.g., maintenance, repair, etc.) is reduced by a yet-to-be-specified percentage as compared to that of the first crew increment - For this objective, "reducing logistics support" means reducing spares and maintenance items brought from Earth to support each crew. Approaches that have been considered include reliability improvements, repurposing of delivered elements, repair, and obtaining or constructing items using local materials.

\section{Mars Surface Field Station (Example)}

Figure 5 provides an expanded view of a centrally located Mars Surface Field Station within Jezero Crater (used only as an example). This figure illustrates how specific functions would be grouped in "zones" to keep related activities in relatively close proximity, but also isolates other activities (e.g., landing zones) to reduce the potential for collateral damage (e.g., debris lofted by lander or Mars Ascent Vehicle (MAV) engines).

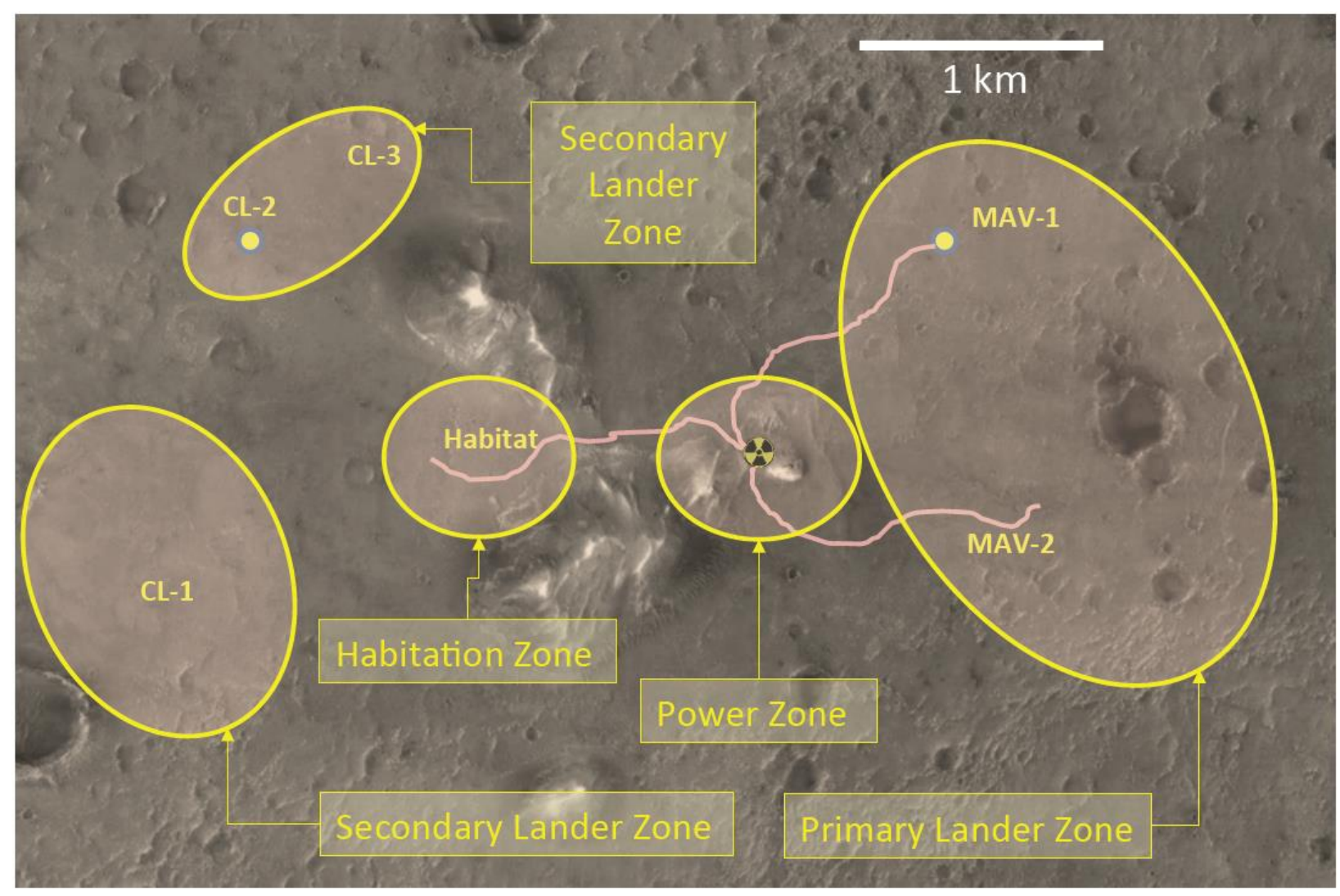

Fig. 5 View of notional Mars Surface Field Station (Mars Surface Proving Ground phase) layout for a centrally located site within Jezero Crater.

These zones can be described as follows: 
- Habitation Zone - This area will be used for the majority of the fixed surface infrastructure of the Mars Surface Field Station, such as the crew habitat, logistical storage, crop growth (once this capability has proven to be feasible and sustainable), and research facilities. Site improvements are likely, such as preparing specific foundations for these infrastructure elements, clearing designated roadways to help minimize dust caused by vehicle movement, etc. This area would be centrally located among the other zones described below.

- Power Zone - As currently envisioned, the infrastructure at a Mars Surface Field Station will be powered by nuclear power systems. As a result these systems will need to be isolated from the crew and other infrastructure to minimize the potential for radiation damage. There are several ways in which this could be accomplished: shielding mass, brought from Earth or locally acquired, that is built up around these systems; use of local terrain features such as shallow depressions or, as illustrated in this example, raised terrain in the form of low hills; or simply distance from potentially affected systems. The actual site selected for the Mars Surface Field Station will determine which of these options is most compatible and effective with the rest of the Field Station layout.

- Primary Lander Zone - This area is primarily intended for the use of the MAV. Each crew will require one of these vehicles to return to the in-space transportation vehicles that will transport them back to Earth. Consequently, this area has the highest potential for improvements, such as: designated landing sites that may be improved by building berms or improving the surface to minimize debris that may be thrown up by the lander delivering the MAV; landing beacons to guide landers to a much more precise landing than otherwise possible; or prepositioned power cables used for generating liquid oxygen (for ascent propellant) and maintaining all cryogenic propellants in their liquid state.

- Cargo Lander Zone(s) - This area is intended for use primarily by cargo landers. Therefore, these zones are located closer to the habitation area, which is presumed to be the most likely area for the cargo to be used. Site improvements such as those described for the Primary Lander Zone would not have as high a priority, because protecting a lander after its cargo has been delivered will not be as important.

When developing approaches for the Mars Surface Field Station, we propose the re-purposing of elements used for resupply (for the initial crews during the Emplacement phase). Elements such as pressurized logistics carriers can provide additional pressurized volume for the crew at the field station and provide facilities to help achieve the key 
objective of the field station: to test, demonstrate, and validate system and subsystem reliability, maintainability and sustainability.

The concept for a dual use of the logistics carriers and internal packaging system produces a "kit-of-parts" that can potentially be reconfigured and used to assemble the Mars Surface Field Station or other structures. Also, by requiring that all packaging systems be dual-use, it could be possible to reduce the overall mass needed on the Mars surface for the EMC.

\section{Utilization Phase}

A Utilization phase as defined earlier is beyond the scope of previous NASA assessments, although the topic has been discussed in a variety of technical and fictional forms. New work is underway to develop a description of the Utilization phase in sufficient detail for it to assist in defining activities that must take place during the Mars Surface Proving Ground phase and be accounted for during early development in the Emplacement phase.

The most defining feature of the Utilization phase is Earth independence, so there are some obviously needed capabilities that have long been recognized and evaluated in previous studies: a local source of water, food growth, enhanced radiation protection, construction projects (e.g., foundation improvement and surface stabilization including landing pads, roads, berms, etc.), light manufacturing (initially to assist in maintenance and repair but growing to enhance and expand other capabilities), etc. As an initial step, previous studies in these areas are being gathered and reviewed for relevance to the EMC.

\section{Summary}

This paper provides a summary of a three-phase approach within the EMC towards pioneering an extended human presence on Mars that is Earth independent. As described, there are many options that might determine how this objective would be realized. Furthermore, there is real value in properly identifying and defining key top-level decision criteria, using these criteria to evaluate options, and the capabilities required for those options. This will enable NASA to examine many different mission objectives, trajectories, vehicles, and technologies, and the benefits they might hold in planning human missions to the Mars surface in the 2030s. A specific approach will evolve over time within the framework of the EMC.

\section{References}

[1] "pioneering" Merriam-Webster.com. 2015. http://www.merriam-webster.com/dictionary/pioneer (January 2015). 
[2] "independent" Merriam-Webster.com. 2015. http://www.merriam-webster.com/dictionary/independent (January 2015).

[3] Billick, I., Babb, I., Kloeppel, B., Leong, J.C., J. Hodder, J. Sanders, and H. Swain, 2013., "Field Stations and Marine Laboratories of the Future: A Strategic Vision," National Association of Marine Laboratories and Organization of Biological Field Stations [http://www.obfs.org/fsml-future], 2013.

[4] Merrill, R.G., Chai, P., and Qu, M., “An Integrated Hybrid Transportation Architecture for Human Mars Expeditions,” AIAA Space Conference and Exposition, Pasadena, CA, 2015.

[5] Salisbury Frank B., "Lunar Farming: Achieving Maximum Yield for the Exploration of Space”, HortScience, No. 26, July, 1991, pp 827-833. 